C OLD S PRING HARBOR

Molecular Case Studies

Cold Spring Harb Mol Case Stud 5: a004564 (2019)

\title{
Corrigendum: 1q21.1 deletion and a rare functional polymorphism in siblings with thrombocytopenia- absent radius-like phenotypes
}

Seth A. Brodie, Jean Paul Rodriguez-Aulet, Neelam Giri, Jieqiong Dai, Mia Steinberg, Joshua J. Waterfall, David Roberson, Bari J. Ballew, Weiyin Zhou, Sarah L. Anzick, Yuan Jiang, Yonghong Wang, Yuelin J. Zhu, Paul S. Meltzer, Joseph Boland, Blanche P. Alter, and Sharon A. Savage

In the article noted above, the middle initial for coauthor Joshua J. Waterfall was initially listed incorrectly. This has been corrected in the author list, as noted here and in the article online.

doi:10.1101/mcs.a005116 


\section{COLD SPRING HARBOR Molecular Case Studies}

\section{Corrigendum: 1q21.1 deletion and a rare functional polymorphism in siblings with thrombocytopenia-absent radius -like phenotypes}

Seth A. Brodie, Jean Paul Rodriguez-Aulet, Neelam Giri, et al.

Cold Spring Harb Mol Case Stud 2020, 6: a005116

Access the most recent version at doi: $10.1101 / \mathrm{mcs} . a 005116$

\section{License}

Email Alerting Receive free email alerts when new articles cite this article - sign up in the box at the Service top right corner of the article or click here. 